\title{
An integrated approach for the assessment of the Aedes aegypti and Aedes albopictus global spatial distribution, and determination of the zones susceptible to the development of Zika virus
}

\author{
José Santos ${ }^{\mathrm{a}}$, Bruno M. Meneses ${ }^{\mathrm{b}, *}$

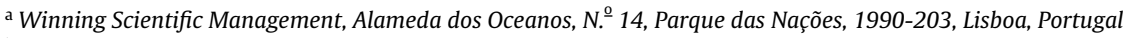 \\ ${ }^{\mathrm{b}}$ Centre for Geographical Studies, Institute of Geography and Spatial Planning, Universidade de Lisboa, Rua Branca Edmée Marques, 1600-276, Lisboa, \\ Portugal
}

\section{A R T I C L E I N F O}

\section{Article history:}

Received 15 June 2016

Received in revised form

23 December 2016

Accepted 16 January 2017

Available online 19 January 2017

\section{Keywords:}

Ae. aegypti

Ae. albopictus

Spatial analysis

Susceptibility of Zika virus

\begin{abstract}
A B S T R A C T
The Zika virus, one of the new epidemic diseases, is reported to have affected millions of people in the past year. The suitable climate conditions of the areas where Zika virus has been reported, especially in areas with a high population density, are the main cause of the current outbreak and spread of the disease. Indeed, the suitable climatic conditions of certain territories constitute perfect breading nest for the propagation and outbreak of worldwide diseases. The main objective of this research is to analyze the global distribution and predicted areas of both mosquitoes Ae. aegypti and Ae. albopictus which are the main vectors of Zika virus. Physical (SRTM) and climatic variables (WorldClim) were used to obtain the susceptibility maps based on the optimum conditions for the development of these mosquitoes. The susceptibility model was developed using a Species Distribution Model - correlative model, namely the Maximum Entropy, that used as input the spatial references of both vectors (Dryad Digital Repository).

The results show the most important classes of each independent variable used in assessing the presence of each species of mosquitoes and the areas susceptible to the presence of these vector species. It turns out that Ae. aegypti has greater global dispersion than the Ae. albopictus specie, although two common regions stand out as the most prone to the presence of both mosquito species (tropical and subtropical zones).

The crossing of these areas of greater susceptibility with areas of greater population density (e.g. India, China, Se of USA and Brazil) shows some agreement, and these areas stand out due to the presence of several records of Zika virus (HealthMap Project).

In this sense, through the intersection of susceptibility and human exposure the areas with increased risk of development and spread of Zika virus are pinpointed, suggesting that there may be a new outbreak of this virus in these places, if preventive measures are not adopted.
\end{abstract}

(c) 2017 Elsevier B.V. All rights reserved.

\section{Introduction}

Certain species of mosquitoes are responsible for the transmission of several viruses that affect humans and animals, as for example Flavivirus type mosquitoes that belong to the Flaviviridae family (Wikan et al., 2016). Several recently published studies establish cause-effect relationships in the dissemination of certain epidemic viruses (Ayres, 2016; Capinha et al., 2014; Kraemer et al., 2015a,b).

\footnotetext{
* Corresponding author.

E-mail addresses: jose.santos@winning.pt (J. Santos), bmeneses@campus.ul.pt (B.M. Meneses).
}

Among the many known viruses the dengue, yellow fever, Japanese encephalitis, West Nile and Zika (ZIKV) are examples of viruses transmitted by mosquitoes that cause millions of infections every year around the world (Wikan et al., 2016). The ZIKV, transmitted by vectors Ae. aegypti and Ae. albopictus, is an emerging pathogen regarded as a major epidemic in many parts of the world (e.g. French Polynesia, Thailand, Philippines, Easter IslandSouth Pacific, Brazil, and others) (Ayres, 2016; Bierlaire et al., 2014; Buathong et al., 2015; Ioos et al., 2014; Lancet, 2016; Musso et al., 2014; Petersen et al., 2016).

ZIK is an arbovirus (virus transmitted by arthropods) of the Flaviviridae family (Ioos et al., 2014) that was first isolated in Uganda (1947) (Ioos et al., 2014) from a batch of Aedes mosquitoes caught in 
the wild (Boorman and Porterfield, 1956; Dick, 1952). Despite this first report ZIKV has only been deemed as emergent since 2007.

The virus transmission is mostly done via the bite of mosquitoes of the Culicidae family and the Aedes genus (Ioos et al., 2014), namely the species Ae. aegypti, Ae. albopictus and Aedes polynesiensis; the latter specie is manly confined to Polynesia. The species Ae. aegypti and Ae. albopictus (more commonly known as Asian Tiger Mosquito) are the two most common vectors in the areas where ZIKV has been isolated (Musso et al., 2014). There is a comprehensive literature about both species due to their importance in the transmission of several diseases including dengue, yellow fever and several other worldwide diseases. The transmission potential of ZIKV is comparable to those of dengue and chikungunya viruses (Nishiura et al., 2016).

The ZIKV virus has recently been the focus of study all over the world, due to its fast spread and transmission via mosquitoes and due to the high number of people infected (400.000 cases estimated in 24 states of Brazil) (Ayres, 2016); the studies stress the cases associated with microcephaly in newborn babies (Ayres, 2016; Goorhuis et al., 2016; Lancet, 2016; Petersen et al., 2016). Another key factor in ZIKV transmission is the spread via people who travel from infected locations to their home countries contributing towards an increase in the number of infections (Goorhuis et al., 2016; Nhan et al., 2014) outside the affected areas. To address this problem several countries (e.g. EU/EEA Member states) have adopted mitigation measures to control the ZIKV epidemic, particularly the screening of people and goods coming from countries with ongoing Zika virus transmission. In this sense, the determination of the geographical locations with higher probability for the occurrence of ZIKV main vectors, bearing in mind the existence of this virus and its potential spread, has become increasingly important.

The evaluation of the susceptibility of the occurrence of a given phenomenon, such as the spread of ZIKV or of natural phenomena, depends on the integration of specific factors that allow the identification of areas of probability for the occurrence of the phenomenon (Julião et al., 2009; Meneses, 2011). In the case of ZIKV, the integration of variables that allow the determination of optimal locations for its spread are based mainly on the optimum conditions for the development of vector mosquitoes responsible for ZIKV transmission. By crossing the susceptibility with human exposure, it is possible to determine the areas at risk of development and spread of ZIKV. This assumption is based on other works that crossed the probability of occurrence of a given phenomenon in a territory with the human exposure to that phenomenon (Bell and Glade, 2004; Julião et al., 2009; Kappes et al., 2012; Meneses, 2011; Schmidt et al., 2011).

The identification of the bioclimatic optimum conditions such as temperature, humidity, among others, are fundamental to understand the development of certain species of mosquitoes (Kraemer et al., 2015a,b; Luz et al., 2008). Other researches point out the importance of selecting predictor variables in spatial modeling that should be biologically meaningful to the species, eco-physiological tolerances, or habitat requirements (Bennetsen et al., 2016; Guisan and Zimmermann, 2000).

Some studies that aim to assess the global distribution of other viruses also used environmental information to estimate the transmission and for the identification of areas where the virus may spread to in the future, e.g. the global distribution and environmental suitability for the chikungunya virus (Nsoesie et al., 2016). However, the optimal ranges of the environmental variables that integrate the assessments of the presence of certain species of mosquitoes responsible for the transmission where are not discussed.

Following these assumptions, the main goal of this research is to predict, at global level, the most suitable spatial locations for the development of Ae. aegypti and Ae. albopictus mosquitoes and to determine, based on occurrence records, the locations where the virus is most likely to develop. The results obtained are fundamental to establish preventive measures to mitigate and control the ZIKV virus epidemic.

In this paper, a correlative Species Distribution Model (SDM) commonly known as Maximum Entropy was used. SDM are numerical tools that combine observations of species occurrence or abundance with environmental estimates (Elith and Leathwick, 2009). These models which combine statistical models, environmental data and information technology are very useful tools to describe biological patterns in terms of their relationship with geographical and environmental conditions (Elith and Leathwick, 2009).

\section{Data and methods}

\subsection{Climate, elevation and population data}

Four climate variables were used, namely mean temperature of warmest quarter and coldest quarter, precipitation of wettest quarter and driest quarter, which represent seasonal and extreme temperatures (Capinha et al., 2014). These variables were obtained from WorldClim (Hijmans et al., 2005) for the period 1950-2000 with a spatial resolution of 30 arc-seconds $\left(1 \mathrm{~km}\right.$ and $0.86 \mathrm{~km}^{2}$ at the equator). The use of environmental information of quarter provides a better understanding and geographical representation of trends between climate variations. A quarter (three months) represents an extreme and limiting environmental factor that can be used to produce higher predicted values response.

To explain the variation of the height at which both mosquito species occur, the elevation of the location was chosen as another physical variable. This variable was extracted from the Shuttle Radar Topography Mission (SRTM). The elevation of the site does not affect directly the species distribution but rather the changes in temperature and air pressure which vary with the elevation (Pearson, 2008).

The bioclimatic conditions were defined based on the available literature (Kraemer et al., 2015a,b; Musso et al., 2014).

The population density of the World for the years 2015 was provided by the Socioeconomic Data and Applications Center (SEDAC) at a grid basis.

All these variables are described in Table 1 . The records of the selected climatic variables are restricted to the 1950-2000 period (Hijmans et al., 2005).

\subsection{Vector data}

The main Zika vectors are the species Ae. aegypti and Ae. albopictus (Musso et al., 2014). The geographical distribution of both species was obtained from the Dryad Digital Repository. The database, containing the occurrence records of the Ae. aegypti and Ae. albopictus, has information for the period 1960-2014 collected from multiple sources. The methods of data collection, description and validation of this database are described in (Kraemer et al., 2015a,b).

The database contains a total of 19,930 and 22,137 spatially unique occurrence records for Ae. aegypti and Ae. albopictus respectively. According to the authors (Kraemer et al., 2015a,b) this database aimed to provide a comprehensive set of data based on occurrences ever recorded globally, including their respective dates, to allow researches and policy makers to use it for their own purposes. These assumptions from the authors and methods used were a fundamental factor for selecting this database for our work. Another reason to choose this database is that it can be used 
Table 1

Variables and data occurrence from Zika species vector.

\begin{tabular}{|c|c|c|c|}
\hline Data & Format & Spatial Resolution & Source \\
\hline Mean temperature of warmest quarter & Raster & 30 Arc-seconds ( 1 km) & WorldClim \\
\hline Mean temperature of coldest quarter & Raster & 30 Arc-seconds (1 km) & WorldClim \\
\hline Precipitation of wettest quarter & Raster & 30 Arc-seconds ( 1 km) & WorldClim \\
\hline Precipitation of driest quarter & Raster & 30 Arc-seconds (1 km) & WorldClim \\
\hline Altitude (elevation above sea level) (m) & Raster & 30 Arc-seconds ( 1 km) & Shuttle Radar Topography Mission (SRTM) \\
\hline Ae. aegypti (occurrence records) & Vector & Not applicable & Dryad Digital Repository \\
\hline Ae. albopictus (occurrence records) & Vector & Not applicable & Dryad Digital Repository \\
\hline Population Density 2015 & Raster & 30 Arc-seconds ( 1 km) & SEDAC \\
\hline
\end{tabular}

to investigate and to predict locations and it was first used in an ecological niche modeling framework (Kraemer et al., 2015a,b).

The occurrence records for the period 1960-2000 alone were originally selected from the database to comply with the temporal resolution of the selected climate data set (see below). The records pertaining to both species were substantially reduced to a final number of occurrence of 2273 and 1924 spatially unique occurrence records for Ae. aegypti (Fig. 1) and Ae. albopictus, respectively (Fig. 2). These occurrences were registered in 87 countries most of which are located in Southeast Asia/America (Ae. aegypti) and North America/Southeast Asia (Ae. albopictus).

The occurrences between 2001 and 2014 have been used to validate the predicted distribution of the occurrence data between 1960 and 2000. To validate this model the predicted and ROC (receiver operating characteristic) curves were used. The ROC plot is obtained by plotting all sensitivity values on the $Y$ axis against their equivalent values for all available thresholds on the $\mathrm{x}$ axis (Fielding and Bell, 1997). The $\mathrm{x}$ axis represents the specificity (fractional predicted area) and the y axis represents the sensitivity (omission rate).

The area under the ROC curve (AUC) ranges from 0 to 1 where 1 indicates a perfect discrimination, 0.5 a predictive discrimination that is no better than a random guess and $<0.5$ indicate performance worse than random (Elith et al., 2011, 2006).

The two mosquito species have different geographical distributions because Ae. aegypti is a predominantly urban vector that uses the abundance of artificial containers as larval sites and feeds almost exclusively on human blood, whereas Ae. albopictus is more often found in peri-urban and rural environment (Kraemer et al., 2015a,b).

The analysis of the spatial distribution of both species shows that Ae. aegypti is predominantly found in the tropics and sub-tropics where climate conditions are more propitious for its development. Although climate conditions are crucial for this specie, urban microenvironments provide good conditions for their establishment due to the artificial thermal shelters and human-mediated water supply which overcome unsuitable macroclimatic conditions (Kearney et al., 2009).

Conversely, the Ae. albopictus specie has spread to Europe (mainly to Italy), Asia (Japan and Vietnam) and North America (with a higher incidence in the states of Georgia, Tennessee, Kentucky and Missouri). The Ae. albopictus specie is a new emerging threat due to the novel association of its unusual natural life cycle in urban environments with a highly invasive geographic range, which is still expanding across the world (Grard et al., 2014).

Although there are many databases with records of occurrence of both vector species, such as GBIF and VectorMap, it was found from published literature and national entomological surveys (Kraemer et al., 2015a,b) that the chosen database contains the most comprehensive occurrence dataset to date.

\subsection{Modeling and validating the predicted conditions}

Correlative models, which rely on the association between the species distribution and a set of environmental factors to deduce the drivers of distribution (Capinha et al., 2014), are commonly used by numerous authors to model species spatial distribution (Bell and Schlaepfer, 2016; Jarnevich et al., 2015). These correlative models differ from physiologically-based models, which focus instead on the study of the biological behavior of the specie (Capinha et al., 2014; Phillips et al., 2006).

A correlative model based on the algorithm of maximum entropy - the Maxent model-was used in the current work. This algorithm estimates the target distribution and species occurrence

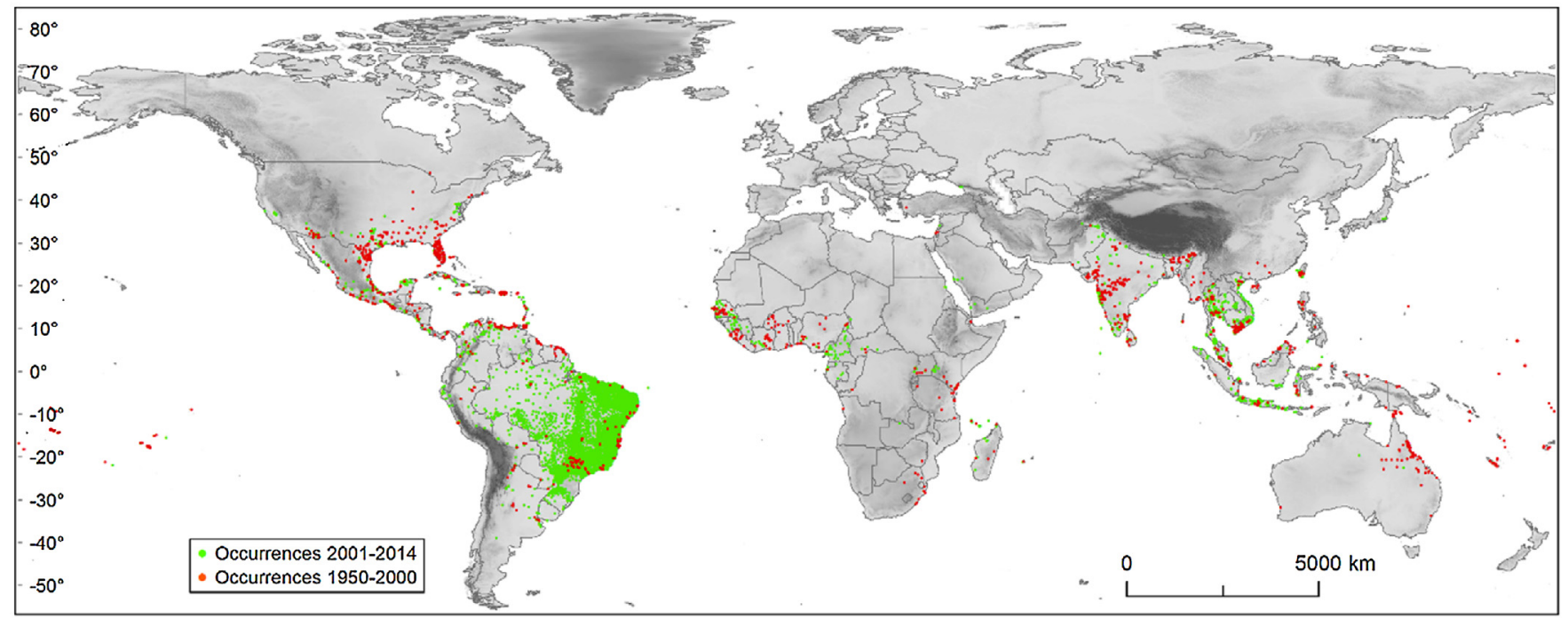

Fig. 1. Ae. aegypti worldwide spatial distribution (1950-2000 and 2001-2014). 


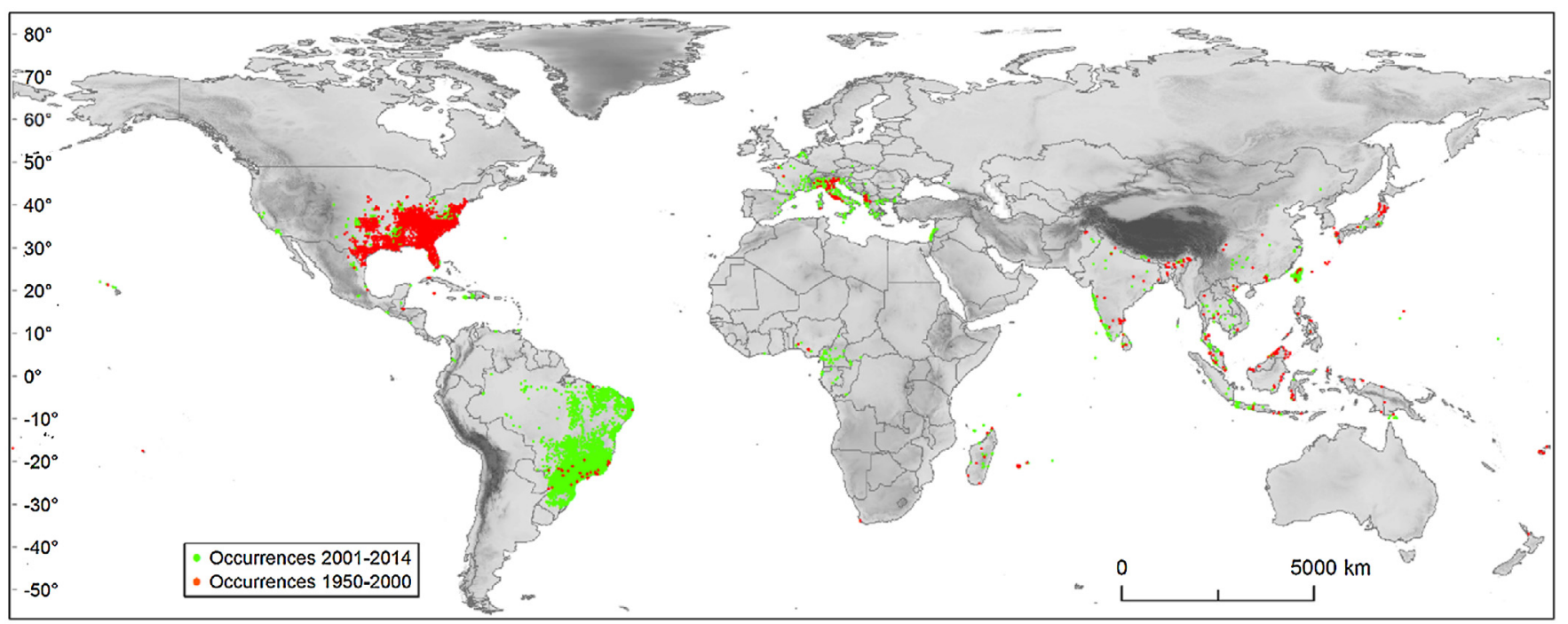

Fig. 2. Ae. albopictus worldwide spatial distribution (1950-2000 and 2001-2014).

records, by finding the distribution of maximum entropy (i.e., that is most spread-out or closest to uniform) (Phillips et al., 2004).

The Maxent software is a general-purpose method for making predictions or inferences from incomplete data (Phillips et al., 2006) and provides an output map with the better predicted conditions for the species under analysis. One of the main advantages of using the Maxent software is that it uses presences-only datasets because the data is linked with environment information. Although the use of absence records in SDM has been shown to improve the model performance (Brotons et al., 2004) these records (absence and false absences) should be used carefully since some of them are unreliable and could skew the final models.

Some methodologies have been developed for the validation of the prediction results, for example the modeling of the probability of the occurrence of a natural phenomenon (landslides, forest fires, etc.) using the Fuzzy Logic or Information Value method. The results are validated at the end of the process through the intersection of the cases used to model it or with a part of the dependent variable (Meneses et al., 2016). Other methodologies use some of the dependent variable for modeling and the remaining to validate the results obtained (random partition). These methods allow the development of success or prediction curves (Tehrany et al., 2013). The partitioning of the dependent variable was used in this work, i.e., the presence records of the mosquitoes for the period 1960-2000 integrated the modeling and the most recent records (between 2001 and 2014) integrated the spatial prediction validation (resulting from the modeling) of the presence of mosquito species under study.

This procedure was performed with the Geographic Information Systems (GIS) (Ilwis software), crossing points of occurrences and the predicted distribution areas in raster (resolution $1 \times 1 \mathrm{~km}$ ).

\subsection{Assessment of susceptible zones to Zika virus development and propagation}

The presence of ZIKV vectors represents a high probability of an outbreak and spread of the virus if the climate conditions are expected to be the optimum. These high probability classes coincide with areas of high population density that pose health problems and have the potential for an outbreak of the disease and a rise in the number of infections. The spatial representation of this susceptibility was obtained using the following equation:

$R_{Z}=\left(A_{a e}+A_{s l}\right) \times P_{d}$
Where $R_{Z}$ is the localization of the ZIKV; $A_{a e}$ is the predicted presence of Ae. aegypti; $A_{s l}$ is the predicted presence of the Ae. albopictus; $P_{d}$ is the population density.

These results were compared with ZIKV presence records provided by the Center for Disease Control and Prevention (CDC) and HealthMap Project (2016 Zika Outbreak) (HealthMap database http://www.healthmap.org/).

\section{Results}

\subsection{Model performance}

The model performance was evaluated based on the gain of each modeled specie. The gain is closely related to deviance which is a measure used in generalized additive and generalized linear models.

The model output for the Ae. aegypti specie has a gain of 1.093, which means the average likelihood of the presence samples is $e^{1.093} \approx 2.98$ times higher than a random background pixel. This value indicates how closely the model is concentrated around the presence samples.

The result obtained from the model gain for the specie Ae. albopictus was $e^{1.405} \approx 4.075$. This value is higher than the one obtained with the model for Ae. aegypti specie which means that the former model (Ae. albopictus) has a better gain defined as the average log probability of the presence samples.

The model used in this study allowed to identify, at global level, the predicted conditions for the presence of vectors ZIKV, Ae. aegypti and Ae. albopictus, i.e., it allowed the distinction between the sites with greater and less probability of occurrence of these vectors and the definition of thresholds in the independent variables associated with the most likely sites (Figs. 3 and 5). Areas shown in red indicate a high probability of suitable conditions for the species, yellow indicates conditions typical of those where the species are found and green implies low predicted probability of suitable conditions. The environmental suitability for virus transmission in an area does not necessarily mean that the virus will arrive and/or become established in that location (Messina et al., 2016). An example of this assumption is the prediction results obtained for the occurrence of the specie Ae. aegypti in Europe and for the occurrence in Africa of the specie Ae. albopictus which will be describe in the next paragraphs. 


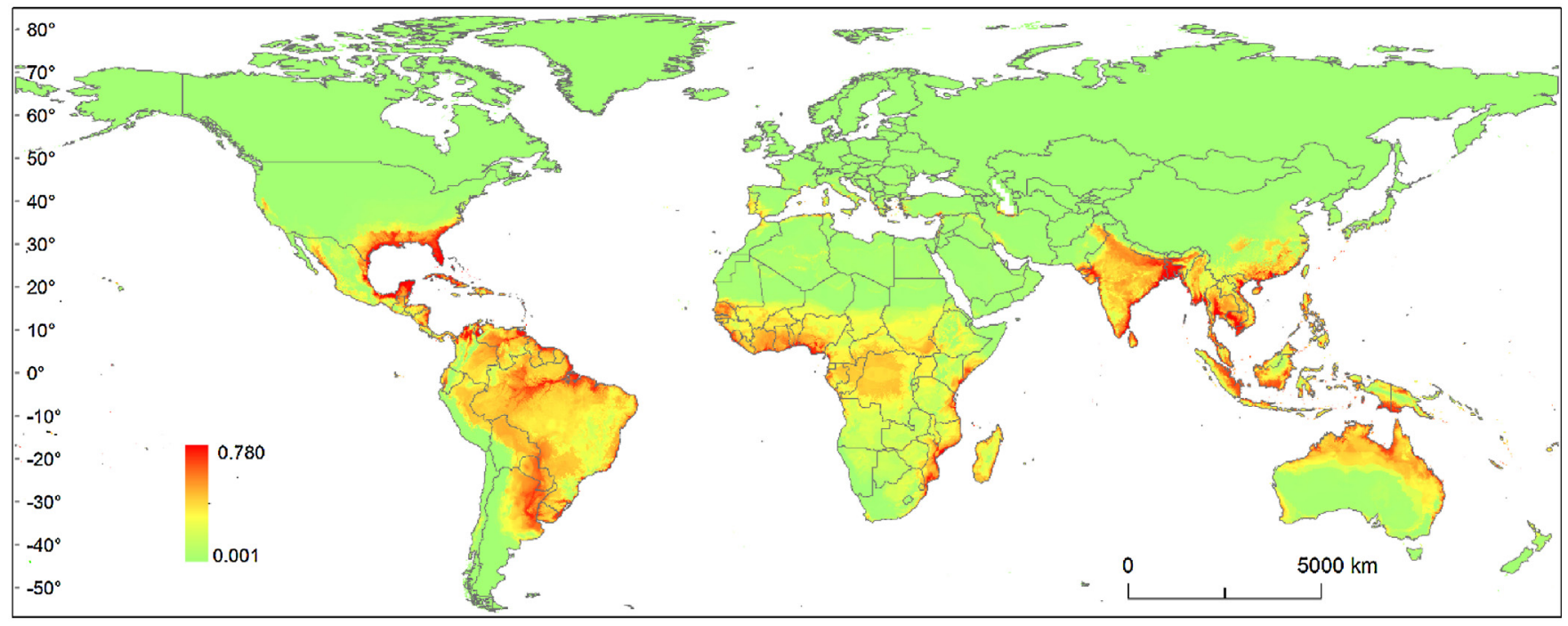

Fig. 3. Global map of the predicted distribution of Ae. aegypti.

Fig. 3 shows a higher probability of the presence of Ae. aegypti in tropical and sub-tropical areas due to the suitable climate conditions. The specie also has a very high probability of occurrence in North America, namely in the southeast coast (e.g. State of Florida), along the coast of China and Southern Asia where most of the occurrences have been reported. Although, so far, there have been no reported occurrences in Portugal, Spain and Italy the predicted overall result is 0.50 . This value indicates that it may be a matter of time until this specie is reported and identified in these countries as a consequence of climate change. The range of distribution of Ae.aegypti is much higher than the range for the specie Ae. albopictus, which is more restricted to certain areas (see Fig. 5).

Fig. 4 shows the receiver operating curve for training data under the ROC curve (AUC). The AUC scores indicate that predictions based on presence-only data can be sufficiently accurate to be used in conservation planning (Pearce and Ferrier, 2000).

In this model, the red line shows the fit of the model to the training data and the AUC $=0.88$ means a near perfect discrimination, hence a high predictive performance of the model.

Most of best models for each species had AUCs $>0.75$ and an additional 14\% had AUCs between 0.7 and $>0.75$ (Elith et al., 2006); The result of this model is largely superior to the models mentioned in Elith et al. (2006).

Ae. albopictus and Ae. aegypti have different geographic distributions due to their different optimum climate conditions tolerance. Fig. 5 shows clearly the very high probability of occurrence of the former specie in parts of the United States of America where it is rapidly expanding its range, as well as in Europe (namely in Italy) and in the southeastern coast of Asia.

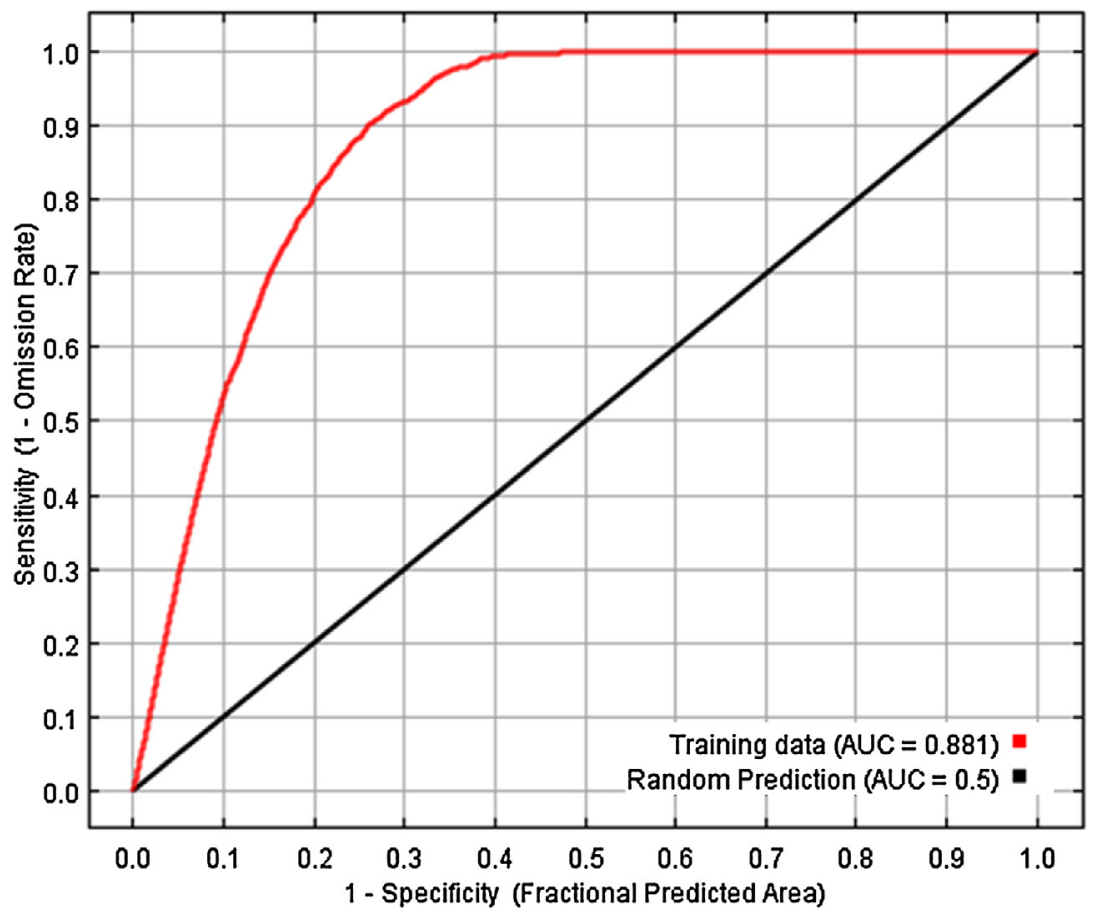

Fig. 4. ROC Curve for Ae. aegypti. 


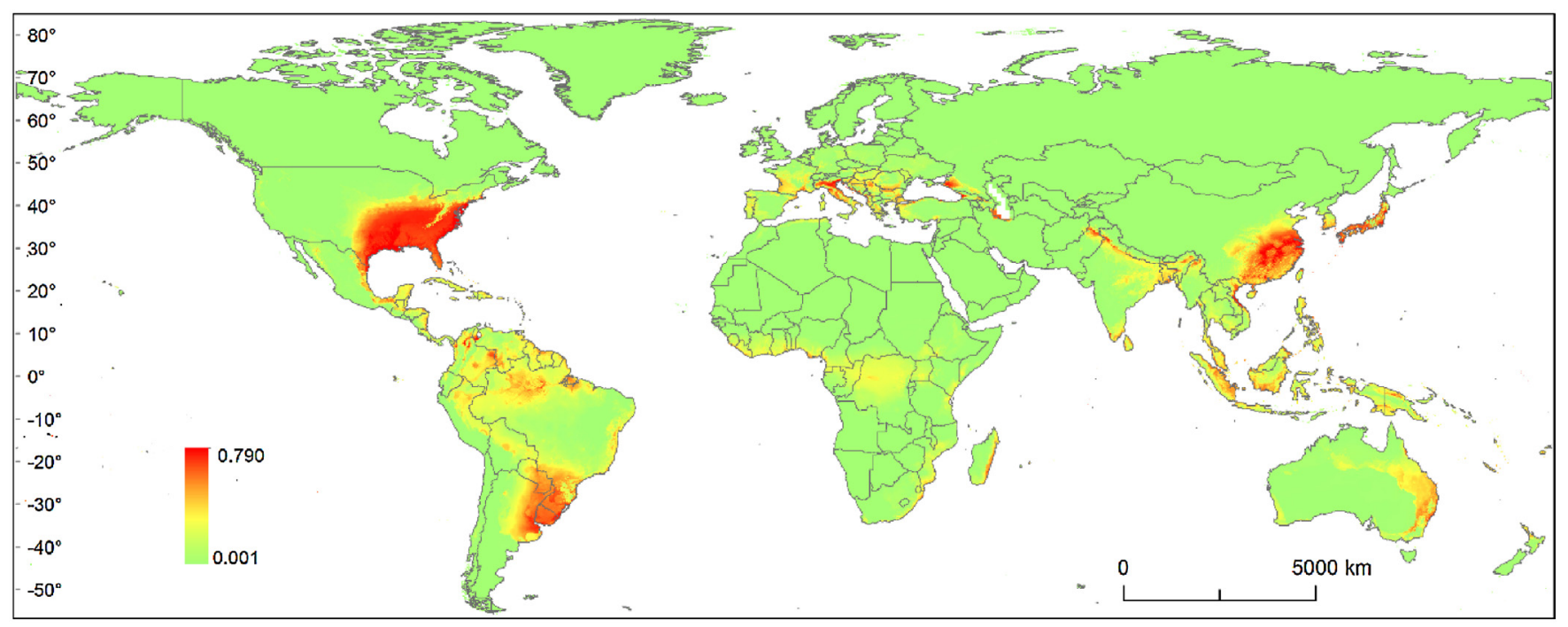

Fig. 5. Global map of the predicted distribution of Ae. albopictus.

Ae. albopictus has been reported in some African countries, namely in Nigeria, Cameroon, Gabon, the Central African Republic, Congo, Côte dílvoire, South Africa and Madagascar (Kraemer et al., $2015 a, b)$. Although the number of reported occurrences in Africa is small, it is not clear if this specie is absent or if it has a small incidence on this continent.

In Brazil, the prediction values for its incidence are also very low compared with the specie Ae. aegypti which allow to assume Differentiated variation of each species as a function of climatic conditions. Indeed, the geographical dispersion of Ae. albopictus is much smaller than that of Ae. aegypti.

The ROC curve (Fig. 6) for Ae. albopictus yielded a value of AUC $=0.90$ which is higher than the Ae. aegypti model (AUC=0.88). This AUC result ( 0.90 for Ae. albopictus) relates to a high predictive performance which indicates the quality of the model and corresponding cross validation. Ae. albopictus higher AUC modeled value can be related with its geographical spread which is more restricted to certain areas, i.e. an accuracy than the more common ones (Elith et al., 2006).

\subsection{Variables contribution}

The model applied to Ae. aegypti is crucial for assessing the contribution and importance of each variable to the spatial distribution model fit. This variable importance is calculated heuristically and thus sensitive to collinearity and the order of variable importance (Wilson et al., 2013). The percent contribution is determined in each iteration of the training algorithm; the increase of the model gain is added to each corresponding variable in the model. The permutation importance is obtained with values of each variable, on training

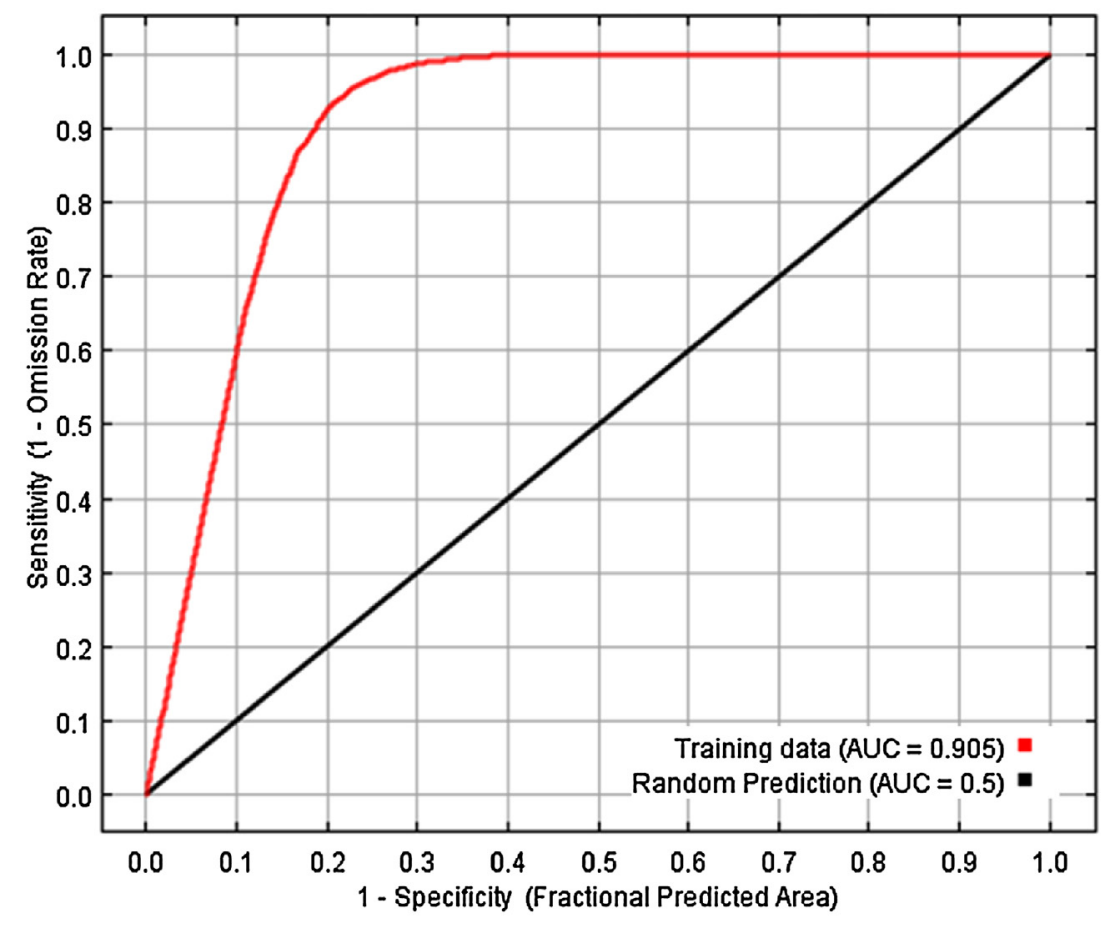

Fig. 6. ROC Curve for Ae. albopictus. 
Table 2

Variable contribution for the specie Ae. aegypti.

\begin{tabular}{|c|c|c|}
\hline Variable & Percent Contribution (\%) & Permutation Importance (\%) \\
\hline Mean Temperature of Coldest Quarter & 44.7 & 42.2 \\
\hline Precipitation of Wettest Quarter & 24.7 & 21.7 \\
\hline Elevation & 21.3 & 17.5 \\
\hline Mean Temperature of Warmest Quarter & 7.0 & 14.6 \\
\hline Precipitation of Driest Quarter & 2.2 & 3.9 \\
\hline
\end{tabular}

presence and background data, which are randomly permuted. The variable contributions from the maximum entropy model for the specie Ae. aegypti are described in Table 2 . The variable with more percent contribution is the Mean Temperature of Coldest Quarter with a contribution, to the Maxent model, of $44.7 \%$. The Precipitation of Wettest Quarter and Elevation have similar contributions (24.7\% and $21.3 \%$ ) and the variable with the smallest percent contribution is the Precipitation of the Driest Quarter (2.2\%).

The variable with a higher permutation importance for the model prediction and reliability is the Mean Temperature of Coldest Quarter (42.2\%) followed by the Precipitation of Wettest Quarter $(21.7 \%)$. The variables Elevation and Mean Temperature of Warmest Quarter are similar with an importance of $17.5 \%$ and $14.6 \%$ respectively. The variable with the poorest model prediction is the Precipitation of Driest Quarter (3.9\%).

The variable contributions to the Maxent modeled Ae. albopictus specie are shown in Table 3. The variable with a higher percent contribution to predict Ae. albopictus presence is precipitation of Driest Quarter (48.7\%) followed by Mean Temperature of Warmest Quarter (24.7\%) and Mean Temperature of Coldest Quarter (15.9\%). The Precipitation of Wettest Quarter (8.1\%) and Elevation (2.6\%) were the less contributive variables.

In terms of permutation importance, which is less sensitive to variable order than to variable importance values (Wilson et al., 2013), the highest contribution with an almost identical permutation value is Precipitation of Driest Quarter (31.7\%) and Mean Temperature of Warmest Quarter (31.4\%). The Mean Temperature of Coldest Quarter and Precipitation of Wettest Quarter have also an almost identical contribution (16\% and $17.8 \%$ ). Regarding permutation importance, the Precipitation of Wettest Quarter has a higher value than the Mean Temperature of Coldest Quarter although in terms of percent contribution it is the opposite. The variable with less importance is Elevation with $3.2 \%$ of permutation.

The response curves show how each environmental variable affects the Maxent prediction. The curves show how the logistic prediction changes as each environmental variable is varied (Phillips et al., 2006).

The plots shown in Fig. 7, for both species, reflect the dependence of predicted suitability on both the selected variable and on dependencies induced by correlations between the selected variable and other variables. This approach has been chosen since strong correlations could exist between variables and the Maxent model makes it easier to interpret.

The assessment of the probability presence of Ae. albopictus has a response curve for the variable "Elevation" in which the best probability of presence occurs in the range of 0 to $150 \mathrm{~m}$. Above $150 \mathrm{~m}$ the probability decreases consistently. The mean temperature of warmest quarter has its maximum value of probability of occurrence between $22^{\circ}$ and $27^{\circ} \mathrm{C}$ although the drop of probability between $24^{\circ}$ and $26^{\circ} \mathrm{C}$ maybe due to missing data. The suitable conditions of temperature for the probability of occurrence of the specie decreases from the $30^{\circ} \mathrm{C}$ mark. The mean temperature of Coldest Quarter increases with the temperature as expected. However, it decreases from $12^{\circ}$ to $21^{\circ} \mathrm{C}$ and it increases again from $21^{\circ} \mathrm{C}$ until it reaches its highest value of $29^{\circ} \mathrm{C}$. The plot of the precipitation of wettest quarter shows an increase of the probability of occurrence from $120 \mathrm{~mm}$ until its maximum around $400 \mathrm{~mm}$. After this highest value, there is a decreased followed by a slight increase due to the number of occurrences on that range of values. The precipitation of the driest quarter shows that the highest probability of occurrence of Ae. albopictus lies between 200 and $300 \mathrm{~mm}$ of precipitation. The number of records drops as the precipitation increases and stabilizes between 350 and $500 \mathrm{~mm}$. The same phenomenon occurs in the range of $510-630 \mathrm{~mm}$.

The analysis of the response curves (Fig. 7) showed that results for the probability of presence of Ae. aegypti are similar to those of Ae. albopictus when the variable elevation is considered This happens due to both species presence at low altitudes and to the same pattern when the altitude increases. Although the decreasing value of probability of Ae. aegypti presence has its break point at $200 \mathrm{~m}$. For higher altitudes, Ae. aegypti has a more irregular variation than Ae. albopictus. The mean temperature of warmest quarter has its highest probability of occurrence between $27^{\circ}$ and $29^{\circ} \mathrm{C}$. Above this optimum interval, there is a consistent drop in the probability of presence which translates the biological response of this specie to very high temperatures. A similar interpretation of the plot in Fig. 7 can be adopted for the mean temperature of coldest quarter: the probability increases with the temperature up to a maximum value between $28^{\circ}$ and $30^{\circ} \mathrm{C}$. The plot of Fig. 7 shows that in the wettest quarter the probability of occurrence increases with precipitation and, although the probability has a small drop at $600 \mathrm{~mm}$ of precipitation, it increases consistently at $1150 \mathrm{~mm}$ Ae. aegypti response curve to the precipitation of driest quarter indicates a maximum probability of presence at $420 \mathrm{~mm}$. After this maximum value the probability decreases with the increase of precipitation.

The validation of the results of the predicted distribution discussed above show that the most recent records of the presence of mosquitoes (2001-2014) are in good agreement with the areas of greater probability of presence of these species.

The graphs of Fig. 8 show that the AUC between the presence of Ae. aegypti (A) and Ae. albopictus (B) (2001-2014) together with the predicted spatial distribution of these mosquitoes, obtained from the records between 1960 and 2000, is very high ( 0.904 for the Ae. aegypti and 0.88 for the Ae. albopictus). In other words, these results

Table 3

Variable contribution for the specie Ae. albopictus.

\begin{tabular}{|c|c|c|}
\hline Variable & Percent Contribution (\%) & Permutation Importance (\%) \\
\hline Precipitation of Driest Quarter & 48.7 & 31.7 \\
\hline Mean Temperature of Warmest Quarter & 24.7 & 31.4 \\
\hline Mean Temperature of Coldest Quarter & 15.9 & 16.0 \\
\hline Precipitation of Wettest Quarter & 8.1 & 17.8 \\
\hline Elevation & 2.6 & 3.2 \\
\hline
\end{tabular}


J. Santos, B.M. Meneses / Act Tropical 168 (2017) 80-90

87
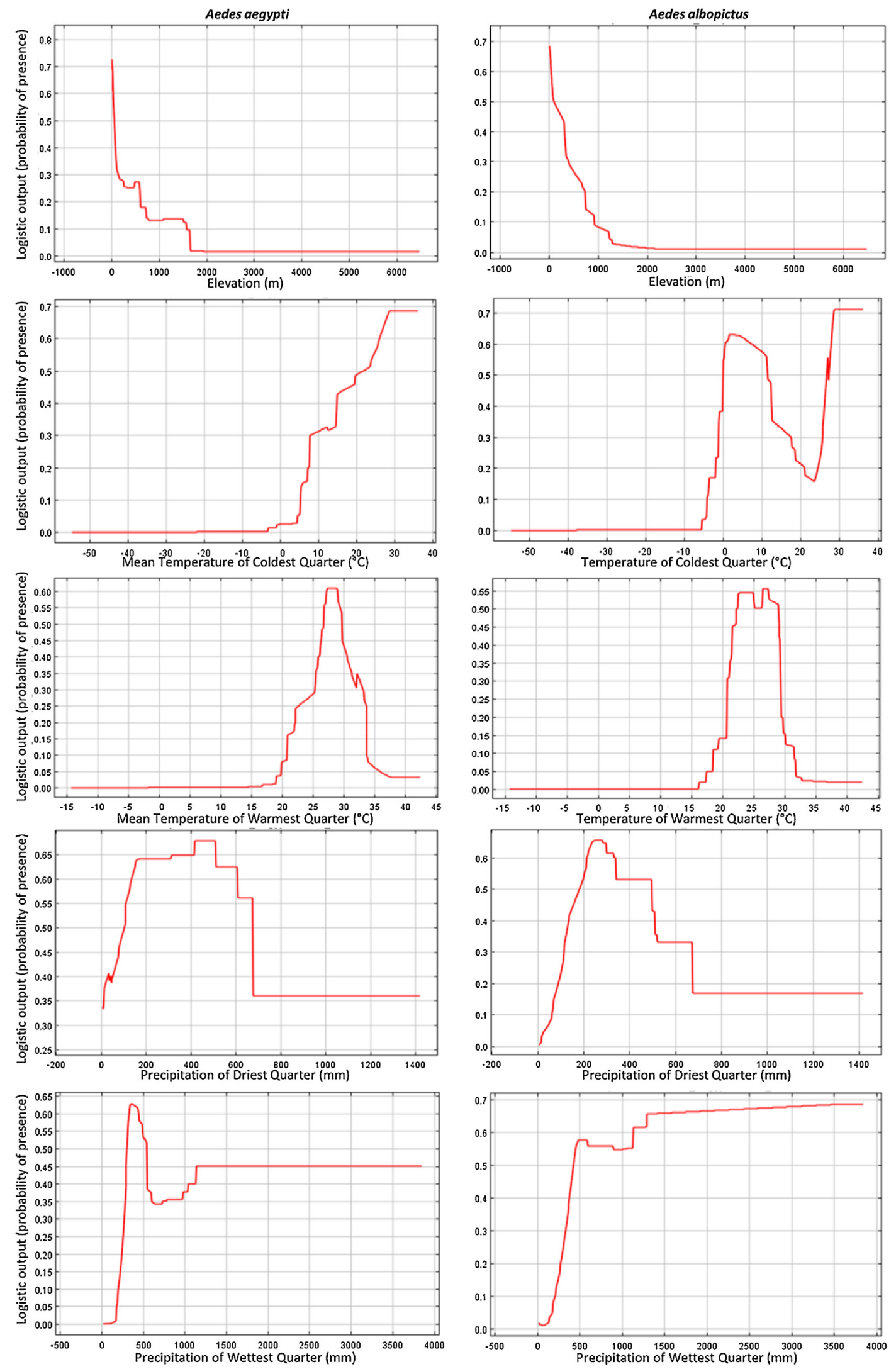

Fig. 7. Response curves for all independent variables that integrated the assessment of the probability presence to Ae. aegypti and Ae. albopictus. 

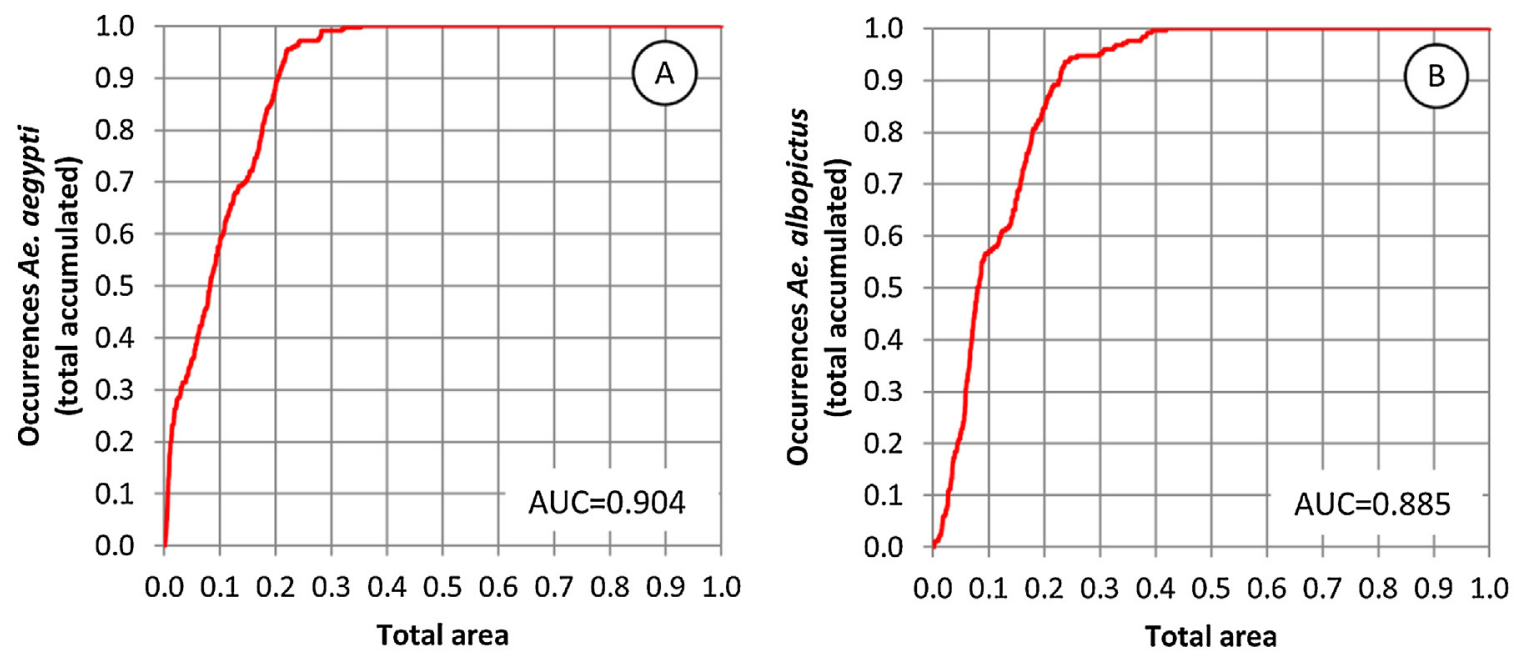

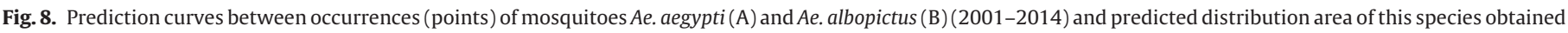
by the occurrence records from the years between 1960 and 2000.

testify the high performance of the model in the determination of areas with higher probability of presence of these species.

\subsection{Potentially susceptible zones to the Zika virus}

To determine the zones potentially susceptible to the Zika virus in populated areas, the overall susceptibility to the two main vectors responsible for the ZIKAV propagation was determined and then this layer was crossed with the population density in the year 2015. The population density was the vulnerable element which allowed the calculation of this overall susceptibility model (Fig. 9). In Fig. 9 the areas with higher susceptibility are clearly in northern India and southern China, that. register high population density but also high values of predicted distribution of Ae. aegypti and Ae. albopictus. In Africa, the countries closest to the equator are highlighted, particularly Nigeria, whereas in America the South of Brazil as well as the Southeast sector of the United States are highlighted as these are the regions of this continent where the presence of Ae. aegypti has mostly been reported. These results are in line with the areas more vulnerable and propitious to ZIKV infections and dissemination through human population that have recently been reported by the Center for Disease Control and Prevention (CDC) and HealthMap Project (2016 Zika Outbreak).

Other world locations also stand out albeit with a lower susceptibility index, as is the case of Northern Australia and the entire equatorial zone. In these cases, the low index is mainly due to the lower population density and the lowest probability of presence of the mosquitoes Ae. aegypti and Ae. albopictus. These results are slightly different than expected since some areas with more reports regarding the presence of both spices have a low population density which has the same results as areas with higher population density and low presence of Ae. aegypti and Ae. albopictus.

\section{Discussion: Ae. aegypti and albopictus presence and Zika virus}

The model used in this research identified areas with high predictive probability for the presence of the species Ae. aegypti and Ae. albopictus at a global scale. The results obtained in this study are similar to those of other recent studies, namely in particular in the identification of areas with high susceptibility where the virus has a high incidence (Bogoch et al., 2016; Rodriguez-Morales et al.,

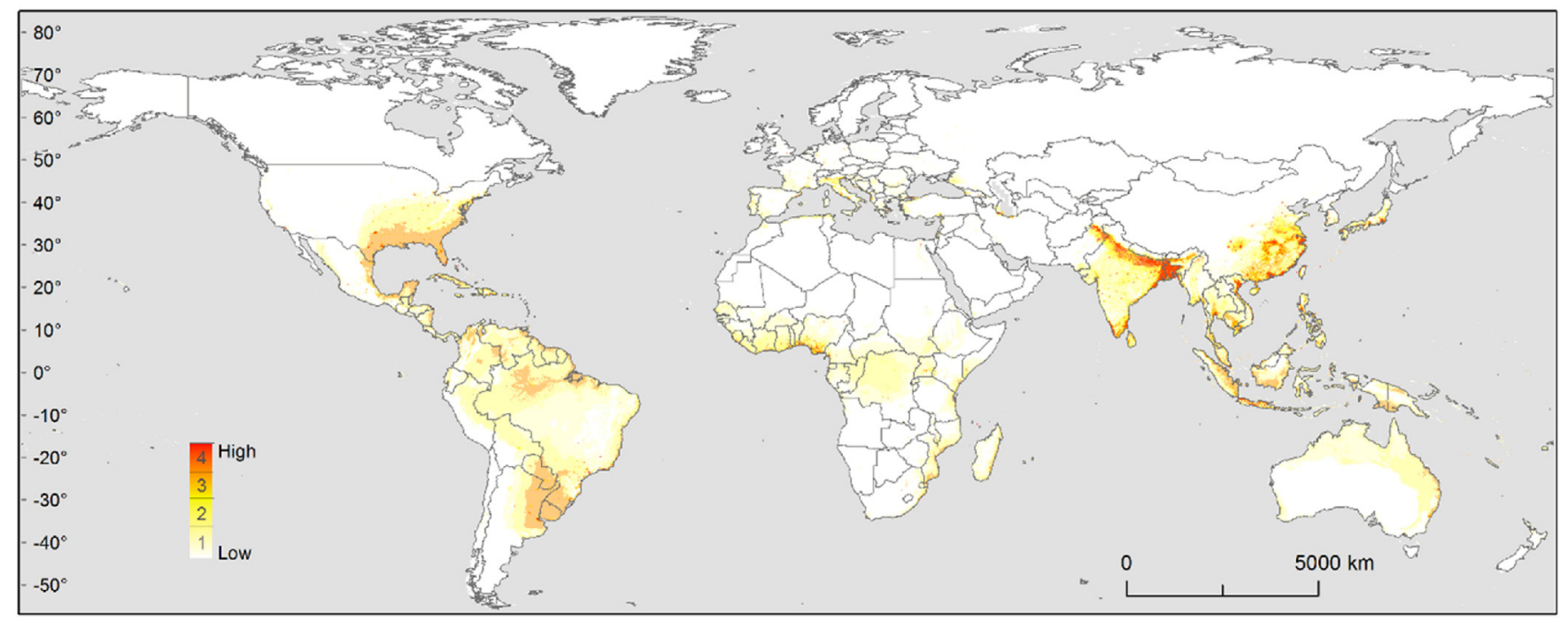

Fig. 9. Global localization of the zones with susceptibility to ZIKV. 
2016), highlighting the importance of the obtained results for the determination of new locations where a ZIKV outbreak is likely.

However, these results are similar to other models (Kraemer et al., 2015a,b) despite the different SDM used (Boosted Regression Trees) and ROC Curve value, the maximum entropy algorithm had a very good performance in determining the predicted distribution of Ae. aegypti and Ae. albopictus due to ROC values.

The formation of well-defined niches with the highest probability of presence of these vectors is closely linked to the high concentration of points in each location with occurrence records (data considered for this model input).

Each independent variable considered in this study of predicted probability of occurrence of Ae. aegypti and Ae. albopictus has different weight or importance on the obtained results; the precipitation and temperature are the most important variables. These climatic factors, which allow the identification of the optimum conditions for the location sites and propagation of these two mosquitoes types, have been mentioned as the most important variables in the prediction of the distribution of these mosquitoes (Kraemer et al., 2015a,b; Luz et al., 2008). Other studies also identified areas of probability of presence of these species of mosquitoes, but the discussion of the contribution of each independent variable (or biophysical bioclimatic) for their presence in a particular location is still incipient and varied depending on the models used in the research (Bogoch et al., 2016; Capinha et al., 2014; Kraemer et al., 2015a,b).

Under the effects of global warming there is a higher probability of ZIKV transmission and spreading to new geographic areas at a higher latitude, in particular areas where the temperature is increasing, for example the Southern European countries (Giorgi and Lionello, 2008; Liu-Helmersson et al., 2015), North and South America, Africa and Asia (projections of surface temperatures by Intergovernmental Panel on Climate Changes - IPCC), due to the favorable future bioclimatic conditions for the development of Ae. aegypti and Ae. albopictus. The climate change applied to species spatial distribution is a common topic of research and is also referred by other authors, namely in the study of Aedes a genus of mosquitoes responsible for the transmission of several diseases (Bogoch et al., 2016; Capinha et al., 2014; Kearney et al., 2009; Khormi and Kumar, 2014; Kraemer et al., 2015a,b). This work has helped to identify the optimal ranges of each climate variable and thus estimate the emergence of new areas with optimal climate conditions for the development of these species of mosquitoes. It has further stressed the integration of climate change spatial information (Aström et al., 2012; Campbell et al., 2015) allowing the adoption of mitigating measures for ZIKV prevention. However, there are other questions that must be answered concerning the transmission of ZIKV, in particular the possible involvement of other species of Aedes mosquitoes in the propagation of the ZIKV, or issues related with reinfection, transmission by blood transfusions, congenital or sexual transmission, as already reported by other authors (Zanluca and Duarte dos Santos, 2016).

The areas of highest susceptibility to ZIKV identified in this research are in line with previous results presented by the HealthMap Project (2016 Zika Outbreak), i.e., areas with more cases of people infected by ZIKV correspond to places with greater susceptibility identified in this study, except for India where the information of the total number of people infected is non-existent. In this case, the evaluation was performed using GIS software (Ilwis), where it crossed the results obtained with the points of the sites where the presence of ZIKV has been registered (Health Map). The accuracy obtained in this crossing exceeds $80 \%$.

In this way, the results of susceptibility to ZIKV allowed the identification of certain areas with a higher population density and higher susceptibility (e.g. North and southeast of India, Bangladesh, southeast of USA, São Paulo and Rio de Janeiro in Brazil, southwest of Nigeria, and southeast of China, in particular the big cities Xangai, Hong Kong). The identification of these areas has great relevance for prevention and reaction to a possible outbreak of ZIKV.

Other studies have assessed the spatial probability of occurrence of the mosquitoes under study (e.g. Late, 2016; Messina et al., 2016), but unlike this study they did not identify the areas at risk of development and spread of ZIKV as they did not consider the human exposure and other variables needed for this type of evaluation.

\section{Conclusions}

The current work has achieved the global spatial representation of the predict areas for the presence of the species Ae. aegypti and Ae. albopictus. The climatic variables used, particularly the temperature and precipitation, represent extreme or limiting environmental factors. Ranges in different periods of the year favorable to the presence of these species were crucial to determine the propensity for occurrence of both species and corresponding worldwide spatial distribution. It was found that the higher concentration of presence records of the two species under study, Ae. aegypti and Ae. albopictus, are correlated with locations where many current ZIKV infections have been reported. Thus, through the predicted areas of ZIKV main vectors it was possible to predict the global distribution and to identify the areas with higher susceptibility. Although this information is very important it only makes sense when it is related with population density, which allows us to quantify more precisely the areas susceptible to ZIKV outbreak and corresponding increase of transmission. In this sense, the results are important for the adoption of preventive measures in the control of ZIKV as the control of epidemic proliferation will be more effective once the places with bioclimatic characteristics suitable for the development of the species Ae. aegypti and Ae. albopictus mosquitoes have been determined.

Future assessments of predicted areas need to take into account the data on climate change, as this would allow the determination of new sites with optimal conditions for the development of mosquito species under study. These results combined with human exposure would be important to identify new areas with potential risk for ZIKV spread.

\section{Acknowledgment}

This work was financed through a grant given by the Institute of Geography and Spatial Planning and Universidade de Lisboa, IGOTUL (BD2015).

\section{References}

Aström, C., Rocklöv, J., Hales, S., Béguin, A., Louis, V., Sauerborn, R., 2012. Potential distribution of dengue fever under scenarios of climate change and economic development. Ecohealth 9, 448-454, http://dx.doi.org/10.1007/s10393-0120808-0.

Ayres, C.F., 2016. Comment Identifi cation of Zika virus vectors and implications for control. Lancet Infect. Dis. 3099, 4-5, http://dx.doi.org/10.1016/S14733099(16)00073-6.

Bell, R., Glade, T., 2004. Multi-hazard analysis in natural risk assessments. Risk Anal. IV, 197-206.

Bell, D.M., Schlaepfer, D.R., 2016. On the dangers of model complexity without ecological justification in species distribution modeling. Ecol. Modell. 330, 50-59, http://dx.doi.org/10.1016/j.ecolmodel.2016.03.012.

Bennetsen, E., Gobeyn, S., Goethals, P.L.M., 2016. Species distribution models grounded in ecological theory for decision support in river management. Ecol. Modell. 325, 1-12, http://dx.doi.org/10.1016/j.ecolmodel.2015.12.016.

Bierlaire, D., Beau, F., Lastere, S., Musso, D., Broult, J., 2014. Virus ZIKA en Polynésie française: hémovigilance receveur. Transfus. Clin. Biol. 21, 234, http://dx.doi. org/10.1016/j.tracli.2014.08.005.

Bogoch, I.I., Brady, O.J., Kraemer, M.U.G., German, M., Creatore, M.I., Kulkarni, M.A. Brownstein, J.S., Mekaru, S.R., Hay, S.I., Groot, E., Watts, A., Khan, K., 2016. Anticipating the international spread of Zika virus from Brazil. Lancet 387 , 335-336, http://dx.doi.org/10.1016/S0140-6736(16)00080-5. 
Boorman, J.P.T., Porterfield, J.S., 1956. A simple technique for infection of masquitoes with viruses. Transmission of Zika Virus. Trans. R. Soc. Trop. Med. Hyg. 50, 238-242.

Brotons, L., Thuiller, W., Araújo, M.B., Hirzel, A.H., 2004. Presence-absence versus presence-only modelling methods for predicting bird habitat suitability Ecography (Cop.) 27, 437-448, http://dx.doi.org/10.1111/j.0906-7590.2004. 03764.x.

Buathong, R., Hermann, L., Thaisomboonsuk, B., Rutvisuttinunt, W., Klungthong, C., Chinnawirotpisan, P., Manasatienkij, W., Nisalak, A., Fernandez, S., Yoon, I.-K., Akrasewi, P., Plipat, T., 2015. Detection of Zika virus infection in Thailand, 2012-2014. Am. J. Trop. Med. Hyg. 93, 380-383, http://dx.doi.org/10.4269/ ajtmh.15-0022.

Campbell, L.P., Luther, C., Moo-Llanes, D., Ramsey, J.M., Danis-Lozano, R., Peterson A.T., 2015. Climate change influences on global distributions of dengue and chikungunya virus vectors. Philos. Trans. R. Soc. Lond. B. Biol. Sci. 370, http:// dx.doi.org/10.1098/rstb.2014.0135 (20140135.).

Capinha, C., Rocha, J., Sousa, C., 2014. Macroclimate determines the global range limit of Aedes aegypti. Ecohealth 11, 420-428, http://dx.doi.org/10.1007/ s10393-014-0918-y.

Dick, G.W.A., 1952. Zika virus (II): pathogenicity and physical properties. Trop. Med. Hyg. 46, 521-534.

Elith, J., R.Leathwick, J.R., 2009. Species distribution models: ecological explanation and prediction across space and time. Annu. Rev. Ecol. Eval. Syst. 40, 677-697, http://dx.doi.org/10.1146/annurev.ecolsys.l.

Elith, J., Graham, C., Anderson, R., Dudik, M., Ferrier, S., Guisan, A., Hijmans, R. Huettmann, F., Leathwick, J., Lehmann, A., Li, J., Lohmann, L., Loiselle, B., Manion, G., Moritz, C., Nakamura, M., Nakazawa, Y., Overton, J., Peterson, A., Phillips, S., Richardson, K., Scachetti-Pereira, R., Schapire, R., Soberon, J., Williams, S., Wisz, M., Zimmermann, N., 2006. Novel methods improve prediction of species' distributions from occurrence data. Ecography (Cop.) 29, 129-151, http://dx.doi.org/10.1111/j.2006. 0906-7590.04596.x.

Elith, J., Phillips, S.J., Hastie, T., Dudík, M., Chee, Y.E., Yates, C.J., 2011. A statistical explanation of MaxEnt for ecologists. Divers. Distrib. 17, 43-57, http://dx.doi. org/10.1111/j.1472-4642.2010.00725.x.

Fielding, A.H., Bell, J.F., 1997. A review of methods for the assessment of prediction errors in conservation presence/absence models. Environ. Conserv. 24, 38-49, http://dx.doi.org/10.1017/S0376892997000088.

Giorgi, F., Lionello, P., 2008. Climate change projections for the Mediterranean region. Glob. Planet. Change 63, 90-104, http://dx.doi.org/10.1016/j.gloplacha. 2007.09.005

Goorhuis, A., von Eije, K.J., Douma, R.A., Rijnberg, N., van Vugt, M., Stijnis, C., Grobusch, M.P., 2016. Zika virus and the risk of imported infection in returned travelers: implications for clinical care. Travel Med. Infect. Dis., 8-10, http://dx. doi.org/10.1016/j.tmaid.2016.01.008.

Grard, G., Caron, M., Mombo, I.M., Nkoghe, D., Mboui Ondo, S., Jiolle, D., Fontenille, D., Paupy, C., Leroy, E.M., 2014. Zika virus in Gabon (Central africa) - 2007: a new threat from aedes albopictus? PLoS Negl. Trop. Dis. 8, 1-6, http://dx.doi. org/10.1371/journal.pntd.0002681.

Guisan, A., Zimmermann, N.E., 2000. Predictive habitat distribution models in ecology. Ecol. Modell. 135, 147-186, http://dx.doi.org/10.1016/S0304 3800(00)00354-9.

Hijmans, R.J., Cameron, S.E., Parra, J.L., Jones, P.G., Jarvis, A., 2005. Very high resolution interpolated climate surfaces for global land areas. Int. J. Climatol. 25, 1965-1978, http://dx.doi.org/10.1002/joc.1276.

Ioos, S., Mallet, H.P., Leparc Goffart, I., Gauthier, V., Cardoso, T., Herida, M., 2014 Current Zika virus epidemiology and recent epidemics. Med. Mal. Infect. 44, 302-307, http://dx.doi.org/10.1016/j.medmal.2014.04.008.

Jarnevich, C.S., Stohlgren, T.J., Kumar, S., Morisette, J.T., Holcombe, T.R., 2015. Caveats for correlative species distribution modeling. Ecol. Inform. 29, 6-15, http://dx.doi.org/10.1016/j.ecoinf.2015.06.007.

Julião, R.P., Nery, F., Ribeiro, J.L., Branco, M.C., Zêzere, J.L., 2009. Guia metodológico para a produção de cartografia municipal de risco e para a criação de sistemas de informação geográfica (sig) de base municipal. In: Anpc, Dgot, Lisboa.

Kappes, M.S., Gruber, K., Frigerio, S., Bell, R., Keiler, M., Glade, T., 2012. The MultiRISK platform: the technical concept and application of a regional-scale multihazard exposure analysis tool. Geomorphology 151-152, 139-155, http://dx.doi.org/10.1016/j.geomorph.2012.01.024.

Kearney, M., Porter, W.P., Williams, C., Ritchie, S., Hoffmann, A.A., 2009. Integrating biophysical models and evolutionary theory to predict climatic impacts on species' ranges: the dengue mosquito Aedes aegypti in Australia. Funct. Ecol. 23, 528-538, http://dx.doi.org/10.1111/j.1365-2435.2008.01538.x.

Khormi, H.M., Kumar, L., 2014. Climate change and the potential global distribution of Aedes aegypti: spatial modelling using geographical information system and CLIMEX. Geospat. Health 8, 405-415, http://dx.doi.org/10.4081/gh.2014.29.

Kraemer, M.U.G., Sinka, M.E., Duda, K.A., Mylne, A., Shearer, F.M., Brady, O.J., Messina, J.P., Barker, C.M., Moore, C.G., Carvalho, R.G., Coelho, G.E., Van Bortel, W., Hendrickx, G., Schaffner, F., Wint, G.R.W., Elyazar, I.R.F., Teng, H.-J., Hay, S.I., 2015a. The global compendium of Aedes aegypti and Ae. albopictus occurrence. Sci. Data 2, 150035, http://dx.doi.org/10.1038/sdata.2015.35.

Kraemer, M.U.G., Sinka, M.E., Duda, K.A., Mylne, A.Q.N., Shearer, F.M., Barker, C.M., Moore, C.G., Carvalho, R.G., Coelho, G.E., Van Bortel, W., Hendrickx, G.,
Schaffner, F., Elyazar, I.R., Teng, H.J., Brady, O.J., Messina, J.P., Pigott, D.M., Scott T.W., Smith, D.L., William Wint, G.R., Golding, N., Hay, S.I., 2015b. The global distribution of the arbovirus vectors Aedes aegypti and Ae. Albopictus. Elife 4, 1-18, http://dx.doi.org/10.7554/eLife.08347.

Lancet, T., 2016. Zika virus: a new global threat for 2016. Lancet 387, 96, http://dx. doi.org/10.1016/S0140-6736(16)00014-3.

Late, M., 2016. Researchers estimate high-risk US cities for Zika transmission. Nations's Heal. - Am. Public Heal. Assoc. 5, 14

Liu-Helmersson, J., Quam, M., Wilder-Smith, A., Stenlund, H., Ebi, K., Massad, E., Rockl??v, J., 2015. Climate change and aedes vectors: 21 st century projections for dengue transmission in europe. EBioMedicine 7, 267-277, http://dx.doi. org/10.1016/j.ebiom.2016.03.046.

Luz, C., Tai, M.H.H., Santos, A.H., Silva, H.H.G., 2008. Impact of moisture on survival of Aedes aegypti eggs and ovicidal activity of Metarhizium anisopliae under laboratory conditions. Mem. Inst. Oswaldo Cruz 103, 214-215, http://dx.doi. org/10.1590/S0074-02762008000200016.

Meneses, B.M., Reis, E., Vale, M.J., Reis, R., 2016. Modeling the probability of surface artificialization in Zêzere watershed (Portugal) using environmental data. Water 8, 1-19, http://dx.doi.org/10.3390/w8070289.

Meneses, B.M., 2011. Susceptibility and Risk of Landslides in Tarouca County Institute of Geography and Spatial Planning of Universidade de Lisboa.

Messina, J.P., Kraemer, M.U., Brady, O.J., Pigott, D.M., Shearer, F.M., Weiss, D.J., Golding, N., Ruktanonchai, C.W., Gething, P.W., Cohn, E., Brownstein, J.S., Khan, K., Tatem, A.J., Jaenisch, T., Murray, C.J., Marinho, F., Scott, T.W., Hay, S.I., 2016. Mapping global environmental suitability for Zika virus. Elife 5, e15272, http:// dx.doi.org/10.7554/eLife.15272.

Musso, D., Nilles, E.J., Cao-Lormeau, V.M., 2014. Rapid spread of emerging Zika virus in the Pacific area. Clin. Microbiol. Infect. 20, 595-596, http://dx.doi.org/ 10.1111/1469-0691.12707.

Nhan, T.-X., Cao-Lormeau, V.-M., Musso, D., 2014. Les infections à virus zika. Rev. Francoph. Des Lab., 45-52, http://dx.doi.org/10.1016/S1773-035X(14)72748-0.

Nishiura, H., Kinoshita, R., Mizumoto, K., Yasuda, Y., Nah, K., 2016. Transmission potential of Zika virus infection in the South Pacific. Int. J. Infect. Dis. 45, 95-97, http://dx.doi.org/10.1016/j.ijid.2016.02.017.

Nsoesie, E.O., Kraemer, M.U.G., Golding, N., Pigott, D.M., Brady, O.J., Moyes, C.L., Johansson, M.A., Gething, P.W., Velayudhan, R., Khan, K., Hay, S.I., Brownstein, J.S., 2016. Global distribution and environmental suitability for chikungunya virus, 1952-2015. Eurosurveillance 21, http://dx.doi.org/10.2807/1560-7917. es.2016.21.20.30234.

Pearce, J., Ferrier, S., 2000. Evaluating the predictive performance of habitat models developed using logistic regression. Ecol. Modell. 133, 225-245, http://dx.doi. org/10.1016/S0304-3800(00)00322-7.

Pearson, R.G., 2008. Species's Distribution Modelling for Conservation Educators and Practitioners, Synthesis. American Museum of Natural History, United States.

Petersen, E., Wilson, M.E., Touch, S., McCloskey, B., Mwaba, P., Bates, M., Dar, O., Mattes, F., Kidd, M., Ippolito, G., Azhar, E., Zumla, A., 2016. Unexpected and rapid spread of zika virus in the americas - implications for public health preparedness for mass gatherings at the 2016 Brazil Olympic Games. Int. J. Infect. Dis., http://dx.doi.org/10.1016/j.ijid.2016.02.001, in press.

Phillips, S., Dudík, M., Schapire, R., 2004. A maximum entropy approach to species distribution modeling. In: ICML (Ed.), Proceedings of the Twenty-First International Conference on Machine Learning. ICML, Banff, Alberta, Canada, pp. 655-662, http://dx.doi.org/10.1145/1015330.1015412.

Phillips, S.J., Anderson, R.P., Schapire, R.E., 2006. Maximum entropy modeling of species geographic distributions. Ecol. Modell. 190, 231-259.

Rodriguez-Morales, A.J., García-Loayza, C.J., Galindo-Marquez, M.L., Sabogal-Roman, J.A., Marin-Loayza, S., Lozada-Riascos, C.O., Diaz-Quijano, F.A., 2016. Zika infection GIS-based mapping suggest high transmission activity in the border area of La Guajira, Colombia, a northeastern coast Caribbean department, 2015-2016 implications for public health, migration and travel. Travel Med. Infect. Dis. 2015-2017, http://dx.doi.org/10.1016/j.tmaid.2016.03. 018.

Schmidt, J., Matcham, I., Reese, S., King, A., Bell, R., Henderson, R., Smart, G., Cousins, J., Smith, W., Heron, D., 2011. Quantitative multi-risk analysis for natural hazards: a framework for multi-risk modelling. Nat. Hazards 58, 1169-1192, http://dx.doi.org/10.1007/s11069-011-9721-z.

Tehrany, M.S., Pradhan, B., Jebur, M.N., 2013. Spatial prediction of flood susceptible areas using rule based decision tree (DT) and a novel ensemble bivariate and multivariate statistical models in GIS. J. Hydrol. 504, 69-79, http://dx.doi.org 10.1016/j.jhydrol.2013.09.034.

Wikan, N., Suputtamongkol, Y., Yoksan, S., Smith, D.R., Auewarakul, P., 2016. Immunological evidence of Zika virus transmission in Thailand. Asian Pac. J. Trop. Med. 1-4, http://dx.doi.org/10.1016/j.apjtm.2016.01.017.

Wilson, J.W., Sexton, J.O., Todd Jobe, R., Haddad, N.M., 2013. The relative contribution of terrain, land cover, and vegetation structure indices to species distribution models. Biol. Conserv. 164, 170-176, http://dx.doi.org/10.1016/j. biocon.2013.04.021.

Zanluca, C., Duarte dos Santos, C.N., 2016. Zika virus - an overview. Microbes Infect. 18, 295-301, http://dx.doi.org/10.1016/j.micinf.2016.03.003. 